$$
\text { "tmcs-konya-report" — 2013/5/24 — 17:07 — page 123 — \#1 }
$$

Report of Meeting Researches in Didactics of Mathematics and Computer Sciences January 25 - 27, 2013 Oradea, Romania

The meeting Researches in Didactics of Mathematics and Computer Sciences was held in Oradea, Romania from the 25th to the 27th of January, 2013 at the Partium Christian University. It was organized by the PhD School of Mathematics and Computer Sciences of the University of Debrecen and the Partium Christian University in Oradea. The meeting was supported by the project: TAMOP4.2.2/B/10/1-2010-0024.

The 61 participants - including 50 lecturers and $21 \mathrm{PhD}$ students - came from 5 countries, 22 cities and represented 35 intstitutions of higher education.

After the warm welcome of professor Szabolcs János Szatmári, the rector of the Partium Christian University in Oradea, Csaba Pajzos, the dean of Faculty of Economics and Hajnalka Kánya the head of Department of Economics, the conference was opened by professor Gyula Maksa, leader of the Didactic Program of the PhD School of Mathematics and Computer Sciences. He welcomed the participants and emphasized the importance of the fact that the conference was held this year at a new location, in Oradea, in Romania.

The subjects presented in the lectures and posters of the conference were of great variety. Beyond the researches on the didactics of mathematics, the use of alternative methods in teaching mathematics, history of mathematics there were several lectures on different subjects in computer sciences.

A very memorable event of the meeting was the sightseeing in the historical centre of Oradea.

Copyright (C) 2013 by University of Debrecen 


$$
\text { "tmcs-konya-report" — 2013/5/24 — 17:07 — page } 124 \text { — \#2 }
$$

In his closing speech, professor Károly Lajkó, ex-leader of the Didactic Program of the PhD School of Mathematics and Computer Sciences and Managing Editor of the journal "Teaching Mathematics and Computer Sciences" appreciated the high quality of the lectures, with special regard to the works of the invited lecturers and PhD students. He also gave his thanks to all the lecturers, the chairs of sessions, and also to the main organizers Eszter Herendiné Kónya and Edith Debrenti, whose work essentially contributed to the success of the conference.

Subsequently, we provide the abstracts of the lectures in alphabetical order of the authors' names.

\section{List of abstracts of lectures}

MARIÁn Ambrozy: The relationship between philosophy and IT in the grammar school

The relationship between philosophy and informatics belongs to intersubject relationships, that need to be analyzed as a part of a grammar school curriculum. It is possible to see common elements among different subthemes.

\section{SzILÁRD ANDRÁs: Inquiry Based Learning: theory and practice}

This lecture has two major aims: to present the IBL (Inquiry Based Learning) and CPD (Continuous Professional Development) concept developed within the framework of the project PRIMAS (Promoting Inquiry Based Learning across Europe) together with a few aspects of theoretical background and to present a series of teaching materials based on these concepts.

SZILÁRD ANDRÁS - GABRIELla ZsOMBORI: Developing reasoning based on a Van Hiele type model

Based on the activities organized by the SimpleX Association and the piloting actions of the PRIMAS project a group of teachers involved in the project developed a Van Hiele type framework for developing reasoning in lower secondary school. We designed a series of IBL activities in order to facilitate the transition between inferior levels of this model. In our short presentation we summarize some theoretical and practical aspects of these activities and we also emphasize some teaching experiences and practical tricks.

\section{EszTer ÁrokszÁLlási: Different representations using in class 9 in Hungary}

How do the different learning methods of different students to the effective learning of mathematics contribute? I made a teaching experiment (13 lessons) 
in a Hungarian secondary school, in Paks with 15 students of age 14-15. I used different representations in teaching algebraic famous products like $(a \pm b)^{2},(a \pm$ $b)^{3}$. In my talk I present the results of the post-test, the student opinions and future plans.

Tünde Baranyai - Gabriella Stark: Teaching of mathematics in the light of the romanian curriculum in basic skills achievement period

In Romania the teaching of mathematics in the basic skills achievement period is according to the curriculum given by the Ministry of Education. In our research, using the content analysis, we present the curriculum of mathematics from basic skills achievement period, in the view of mathematics and curriculum theory. In terms of efficient application of the curriculum of mathematics we formulate recommendations.

KRISZTINA BARCZI: Using so called "guiding questions" in teaching mathematics

Although the statement that teaching problem solving is one of the most important tasks of teaching mathematics might sound a bit worn-out, it is very true. No wonder that the question how to do it effectively arises again and again. One of the solution might be, as suggested by György Pólya, the use of questions ("guiding questions"). How can we use these "guiding questions" in developing students problem solving thinking skills? How can we help students to formulate these questions on their own? In the presentation two problems will be discussed which were taught using cooperative teaching techniques. Furthermore, the effectiveness of students problem solving and their opinion will be mentioned.

\section{Minály Bessenyei: Spiders and loops}

Hungarian mathematicians have played a key role in the 20th century's mathematics, contributing many fields with many fundamental results. The success of Hungarian mathematics, partly, can be traced to a characteristics feature of competition trainings: Many competition problems or their solutions give an insight on modern results.

In the talk, we make an attempt to introduce some ideas of Algebraic Topology and Topological Fixed Point Theory so that, according to our hope, a secondary school student be able to understand them. We start with the next problem. There is a ball-shaped and a torus-shaped planet in the Universe. Can or cannot their spider inhabitants make a difference between the two planets? 


$$
\text { "tmcs-konya-report" — 2013/5/24 — 17:07 — page } 126 \text { — \#4 }
$$

JudiT BoDA: Teaching of Database Management in Geography and Geosciences at the University of Debrecen

The goal of the lecturers working for the Department of Geography and Geoinformatics at the University of Debrecen is to provide the students with a comprehensive and a hands-on based knowledge. During the development of the curriculum we take into consideration the different needs of all the branches associated with the department. The collecting of data from different sources and in diverse formats, and its organizing and processing all play a crucial role. The students have the opportunity to understand the complexity of database management through a series of courses. During their university studies, students learn to use the following softwares: MSExcel, MSAccess, ArcGIS, ArcCatalog, and SOLDeveloper. During their BA studies, students get acquainted with databases that are necessary and useful for their work. They also learn new ways of obtaining data in the future. With the help of their own databases the students will be able use the relational model and the concepts related to it on a skilled level. With the help of courses related to geoinformatics, students can master the basics of SQL language, which they can develop further during their Master program. By building their own SQL server they will also get to know its server side, besides its user side. Those students who obtain their degree in this field will be able to find employment successfully with the help of their complex knowledge.

IGNÁC BonTOVICS: Computer facilities for demonstration of logical operations and measuring of it's comprehension in primary school

There are some resources for teachers to make much more bold and colourful lessons and however make easier learning the necessary skills and experience for children. Also computer is such a tool, that allows not only demonstrate, but we can measure how much the students learn each of logical operations. I would like to introduce my animations, the results and tendencies of our previous measurements in my presentation.

\section{Katalin Bubnó: Mobile programming with AppInventor for Android platform}

Students using mobile phones cause big difficulties for a lot of schools. In most cases teachers think the best practice is to ban these devices to protect themselves from unpleasant consequences. To tell the truth, smartphones and other smart devices are very popular between young people and children, too. We think we must take advantage of children's interests and teach them the clever and ethic use of these tools. Furthermore, we could teach computer programming by mobile phones, better to say mobile programming. Fortunately, we found a school in 
“tmcs-konya-report" — 2013/5/24 — 17:07 — page 127 — \#5

Debrecen where we can try this thesis, so from this September we have been taking a course in mobile communication. Beyond the basic skills of telecommunication we teach application development for Android platform, too. We have chosen a friendly developing environment for children, namely AppInventor for Android published by Google Inc. and MIT in 2010. Now we present this developing tool, our teaching concepts, and our experience as well.

LÁsZLó BUDAI: The development of space-perception in a high school with help of GeoGebra

The formation of more precise space-perception is very important for all the people, because our life is going on in space. We need mapping this onto the sheet of paper often (for example the guide of finding one's way around a city's map, a device of use ...), the interpretation of which not anymore too so plain. GeoGebra DGS is fit for the development of the students' space-perception, onto influencing him in a beneficent direction, of course complementing the traditional devices. I present what kind of opportunities offer themselves for the representation of the different space structures at this moment in the GeoGebra, and the results of the researches made in a related 2011/2012 school year with this.

Kristina Cafikova - Kitti Vidermanova: Solution of Tasks Focused on Every-day Life Using Silent Written Communication

In this article we present the pupils' solutions of the tasks focused on everyday life. These tasks were created to increase of the mathematical key-competencies of 11, 12, 13 years old pupils. For the solution of the tasks we choose the strategy of the silent written communication and pupils' group work. This teaching strategy comes from Germany. We describe this teaching strategy, how we can use it in the teaching process and the advantages and the disadvantages of this strategy.

\section{ANIKó CSÁKÁNy: Mathematics knowledge of engineering university entrants}

At the Budapest University of Technology and Economics students take a diagnostic test in mathematics at the beginning of their first year since 2010 . This paper presents the background and circumstances of implementing this test. Using the tools of didactics it highlights the results of the 3000 participants it gives an overview of the factors that influence succeeding. It also provides an overview of possible steps universities may introduce to help students with diverse background. 


$$
\text { "tmcs-konya-report" — 2013/5/24 — 17:07 — page } 128 \text { — \#6 }
$$

HajnalKa Csapó: Developing the concept of function using a series of IBL activities based on a Van Hiele type framework

In this short lecture we describe a Van Hiele type framework for developing the concept of function and a series of IBL activities which supports the transitions between the first three levels of the Van Hiele model. Some of our activities were implemented at the actions (Talent Days, summer camps) organized by the SimpleX Association and performed with the cooperation of the project PRIMAS (Promoting Inquiry In Mathematics and Science Education Across Europe). Int he last part of the lecture we share some of our teaching experiences, conclusions from these activities.

\section{Edith Debrenti: Results of a Comprehension Test in Mathematics}

In higher education the main subjects are based on the knowledge acquired in high school. Research shows that students enter universities with different levels of basic knowledge. It is very important to be able to apply mathematical knowledge directly. Students often treat practical knowledge separately from the theoretical one. They find it difficult to bind these two types of knowledge or to see the relation between them. Meaningful learning and understanding is a basic aspect of all kinds of learning, and it is even more important in the case of learning mathematics. When students can provide the solution to something they have not learnt directly, when they can use their knowledge in novel situations, this is a sign of a different quality of knowledge, of a deeper understanding. The aim of this research was to measure students' independent thinking and problemsolving skills, as well as to investigate the way they can actively apply their knowledge when solving problems not directly connected to the curriculum. We have investigated the relationship between the different knowledge areas, and levels (operations, understanding, problem and exercise solving) in the case of one hundred economic majors at Partium Christian University.

\section{JÓZSEF FOGARASI: The methods of measuring volatility}

The prices of financial assets and products and services for final consumption have experienced an excessively increasing volatility in the last decade. This has directed the attention of researchers to identify better performing methods for measurement of volatility which resulted in a wide body of literature presenting simple and complex measures of volatility, the later with the capacity of prediction of volatility pattern. This paper summarises the problems why changing volatility causes problems for economic decision makers, presents the characteristics of volatility measurement in different markets for different products and 
"tmcs-konya-report" — 2013/5/24 — 17:07 — page 129 — \#7

assets, and compares the values obtained with different volatility measurement methods. Finally in the conclusion section we draw further research directions and present possible applications.

József Fogarasi - Edit NAGy - ERzséBet SzÁsz: Methodological aspects of investigating the relationship between entrepreneurial performance and corporate social responsibility

Nowadays the discussion about Corporate Social Responsibility (CSR) is not only in developed countries or in association with big companies, but the concept of responsible entrepreneurship was established in emerging economies too. Therefore the aim of our research is the empirical examination of how CSR influences the performance of small- and medium-sized enterprises (SMEs) in Bihar County. The performance of enterprises is evaluated by estimation of total factor productivity (TFP) applying Data Envelopment Analysis (DEA) linear programming method. TFP calculation with DEA is based on Malmquist total factor productivity change index which consists in the assessment of the change in the efficiency frontier for a decision making unit. The obtained TFP scores are used in the second stage for estimating the correlation with environmental variables. Consequently we apply regression analysis for estimating which effect has CSR on the performance of small- and medium-sized enterprises.

EDIT FÖLDESI: Variations for system of equations with multiple variables

In my study, I would like to present the different ways of solving the system of equation taken from György Pólya's 'Mathematical Discovery: On understanding, Learning, and Teaching Problem Solving'. Solving system of equations was considered important by György Pólya as well, since he dealt with it in both his books. Learning how to solve system of equations in secondary school is necessary, because several other topics are based on it. What is more, it is crucial for those, who would like to continue their studies on a higher level when studying algebra, e.g. matrices. I would also like to introduce different ways of solutions that were liked and sometimes disliked by my students. I find demonstrating the different ways of solving a task significant, and therefore I am able to improve my students' creativity, namely their flexibility, resiliency and wit as well.

\section{KATALIN Földesi: Geometric terms in two Swedish curricula and a textbook}

What possibilities do Swedish students get to form geometric terms? Two important sources are curricula, which are mandatory policy documents, and textbooks, which are used studiously every day. What possibilities do these sources 


$$
\text { "tmcs-konya-report" — 2013/5/24 — 17:07 — page } 130 \text { — \#8 }
$$

provide to help students form their own geometric terms? What possible obstacles, that would prevent students from forming their own geometric terms, are present in these sources? I will try to answer these questions in my presentation.

JÁn GunČAga - ŠTefan TKaČIK: The principle of beam balance (scale) in Galileo's Works

Galileo refers to the use of elasticity of materials for construction beams by the principle of beam balance in his revolutionary work "Discourses e Dimostrazioni matematiche intorno a due nuoue Scienze", published in 1638 in Leida. The results can not serve as the calculation of concrete beam, but they are oriented to the changing strength of the beam or girder to change its size. The aim of this contribution is to show the original works of Galileo's use of a simple application of theory to the design and strength design of beams, using mathematical tools in deriving the properties of objects. These examples demonstrate how to use such motivational tools in teaching physics at secondary schools as well as curricular relationship between mathematics and physics.

\section{SARA HershKovitz: Using technology in the mathematics classroom}

In recent years, different countries have published national strategic plans for integrating technology into the education system (Anderson, 2010; ATCS, 2010; Bellanca - Brandt, 2010; Christensen - Horn, 2008;). these plans include development of technological environments that support teaching, learning, and assessment at all levels of education. The integration of digital technology into the mathematics classroom is an ongoing process (Labbord - Straber, 2010, p. 122) which follows this national tendency in different countries. It seems that the process of integrating new technologies into everyday practice is inevitable. The integration of technology into the mathematics classroom reveals new possibilities as well as new pedagogical opportunities (Pierce - Stacey ,2010) that we have to take into account while designing mathematics lessons. In the lecture I'll present examples and possibilities from ICT environment for teaching mathematics as well as for promoting teachers' professional development.

Tünde KÁNTOR: Georg Polya and the visualization of the crystallographic groups of the plane

Georg Polya (1887-1985) was an outstanding mathematician and a famous teacher. He dealt with different parts of mathematics: combinatorics, theory of probability, real- and complex functions, mathematical analysis, geometry, theory of numbers, theory of algebraic equations, mathematical physics. His name is 
"tmcs-konya-report" — 2013/5/24 — 17:07 — page 131 — \#9

connected with modern heuristics. He wrote the books How to solve it?; Mathematical Discovery: On understanding, Learning, and Teaching Problem Solving; Mathematics and Plausible Reasoning I-II. (Induction and Analogy in Mathematics, Patterns of Plausible Reasoning). It is a very remarkable feature of his work to apply figures for the visualization of geometrical theorems. G. Polya and M.C. Escher spoke the same language, the language of geometric figures. Polya's figures on the crystallographic groups gave the inspiration for Escher's tiling.

\section{Anna Klingné TAKÁcs: The examination of the solution of economic tasks}

Differential- and integral calculus is an organic part of the curriculum at our university. We use computerized methods for illustration, comprehension. Last school-year, besides the traditional method, we used the GeoGebra program in the course of teaching integral calculus. This year the program was introduced to support the study of differential calculus and its applications. We investigated how GeoGebra helped students to find the connection between economic problems and their mathematical model. Did students' achievement improve with its use? We show our teaching experiences in these issues.

JUDIT KOLLÁR: The supply of the mathematical knowledge in higher education of economics

An important task of the higher education is to bring the mathematical knowledge of students beginning the education to the same level. The tuition fee introduced in economic studies did not result in that the school students would consider their preparation for the study more seriously, since they can begin the higher education with weaker high school graduation and the corresponding entrance rating. However the high rate of failure at mathematical exams cannot be rationalized by their former mathematical grades. At BGF close up courses were commenced based on an initial assessment of the students' knowledge and skills. Two times a week, during the course relevant notions and essential mathematical theorems were reviewed in connection with university's curriculum. The presentation analyses the efficiency of these close up courses on the bases of different assessments.

\section{Lilla Koreñová: Digital technologies in mathematics education}

In the last decade, digital equipment has become our everyday lives. This environment is new for us, however native for the students and it has appeared in teaching as well. You can find a computer with internet access in every educational institution and on high schools an interactive board is nothing new. It 


$$
\text { "tmcs-konya-report" — 2013/5/24 — 17:07 — page } 132 \text { — \#10 }
$$

is then proper if we take it as a serious question, how can we use these technologies in teaching mathematics. In high school mathematics, new (or updated, "digitized") teaching methods have appeared which support digital technologies. These technologies - and I don't mean purely hardware (computer, tablets, interactive boards, electronic voting devices), but didactic software as well (GeoGebra, Cabri geometry, Derive, WXMaxima, Hot Potatoes, etc.) - don't only make teaching mathematics more interesting, but give space for new teaching methods and forms. In our presentation we demonstrate the possibilities of teaching mathematics in a digital environment with a few examples and share the experience from teaching the subject Digital technologies in teaching mathematics on the Comenius University and the Debrecen University.

Veronika Kovács - Dorka Palotay - Enikő Pozsonyi - Csaba Szabó: High school problems with abstract algebraic background

In most cases students do not observe the direct connection between the material they learn at college and the one they teach at high school. In our talk we present an example where a high school competition problem is handled by elementary linear algebraic tools.

Veronika Kovács - Dorka Palotay - Enikő Pozsonyi - Csaba Szabó: Hungaricum - Graphs connecting science and education

In our talk we unify the demands of modern graph theory and high school material. We interviewed several researchers and high school teachers about their view of implementation graphs into highs cool mathematics. As a result we developed two possible foundations of introducing graphs to students.

\section{PÉTER KöRTESI: Mathematical Playground; Flexagons}

During the activity of the Self-made Mathematics Group of the University of Miskolc we studied some mathematical games and created the so called Mathematical Playground involving the presentation of such games at the Researchers' Night or Open day activities of the university. We use to present the mathematics behind the games and puzzles like Magic squares, Hanoi tower, Nim, Möbius band or Flexagons. The flexagons, we developed for this programme, can be considered as a type of topological model. They are figures made from a sheet of paper, but end up having surprising properties, like many faces appearing by flexing them. We will study the construction of the tetra-tetraflexagons, and and show an interesting applicatiopn to be used as a "magic" leaflet containing the information about three of the faculties of the University of Miskolc. An other 
family of regular flexagons to be studied are the hexaflexagons, we will experiment with them, and discover a bit of their mathematics, the graphs which reveal their inner structure.

\section{ILONA MÁtÉ: Some questions about the algebra's teaching}

In the course of my teaching experience, I have met such items to be taught that had caused serious difficulties for many generations. One of these items is comprised in the 7th grade's syllabus: the beginning of teaching algebra, the numbers substituted by letters. I would like to present an experiment by which I tried to make easier the understanding of this chapter of mathematics for challenged students. The experiment was conducted in the lower-secondary school of Bihardiószeg from Romania, in the school year 2011-2012. I would like to present the course, the results of experiment and my conclusions.

SÁNDOR Molnár: Changes in the content of mathematics courses in economics education

The preparedness of students arriving to higher education has been deteriorating in recent years. Can we maintain the usual requirements against students exiting freshman courses? What consequences follow from the alleviation of requirements? A dramatic deterioration of mathematical competencies is partially balanced by the spreading use of computer programs.

KATALin MunkáCSY: How do educational studies disturb the educational process?

They are exploratory and hypothesis-testing researches also in mathematics education. The exploratory part is often only the preparatory part of the research. I would like to speak about this first stage; because this one gives the new knowledge about our topic. The planning is uncertain, methods are highly variable. One possibility is that the observer tries to stay invisible. The other is when the observer is actively involved in the processes, this method comes from sociological researches, and its name is: participant observation and we can use it in research of mathematics education.

\section{ÖRS NAGY: Research oriented problems in the light of Inquiry Based Learning}

In this lecture we discuss the solution of some well known elementary problem (measuring with unscaled pots, the orbit of a point wise object supposed to an oblique projection, forming squares using matchsticks) from the viewpoint of Inquiry Based Learning. Our focus is on the teaching difficulties and challenges 
arising when dealing with real life problems, that allows (and in an IBL perspective sometimes needs) a deeper analysis or a small research. The problems and teaching materials we present were used in several Professional Development Courses (in the framework of the PRIMAS FP7 project) and student camps (organized by the SimpleX Association) with different age groups. We also discuss some teaching experiences gained during these activities.

IlONA OlÁHNÉ TÉGLÁsI: Forward and backward thinking in problem solving and proofs

During teaching practise we sometimes meet problems and proofs that could be solved easier beginning with the conclusion or result, and analysing it "backwards" to the conditions, than thinking forward from the conditions to the conclusion or result. It could be useful to show pupils the strength of backward thinking strategy beside the natural way, forward strategy of thinking. In my lecture I'd like to show the logical and psychological background of the two ways of thinking. After it I'd like to show some examples of problems and proofs in which we can match the two strategies, regarding the age of pupils to whom they could be taught.

Edita PARTOVÁ: Mathematical knowledge from the Primary school to the University

In our country are usually not organized entrance exams to university that means the teachers would have no information of the students' previous knowledge. The largest number of students on the J. Selye University is studying preschool and elementary school teaching, where the mathematical knowledge was an important requirement in the past. Now entrance exams we replaced by test in first year of study. For several years we follow the students that part of the mathematical knowledge that they will need, as teachers. The test is also a measure of the degree of persistence of the primary mathematical knowledge. These are the initial knowledge for drawing up teacher training programmes because teachers need different mathematical knowledge as ordinary people or as mathematicians. In a lecture we will present an analysis of the results of the test and any other interesting findings.

ERIKA PeRge: Using computer software to teach color theory on different fields of education

After reviewing the concept of "color", I describe the way colors are perceived by the mind, and the features of color perception. I outline the process 
of how color sensation evolved. I introduce new features and updates of my selfdeveloped software, which has been tested as a tool for teaching color theory at the University of Debrecen, Faculty of Civil Engineering, as well as Medgyessy Ferenc Grammar School and Secondary School of Arts (in courses of "applied photography", "applied graphic arts" and "general painting"). I demonstrate our results supporting the efficiency of the software.

Richárd RAKAmazi: Solving Diophantine equations with Gaussian integers in group study session in secondary schools

The aim of the presentation is to show, how we can apply the knowledge of Gaussian integers in solving number theory problems successfully in group study session in secondary school or in mathematics competitions. Complex numbers $z=a+b i$, where $a ; b$ are integers are called Gaussian integers. Complex numbers are not part of the curriculum in secondary schools, therefore neither the Gaussian integers are mentioned. However, if we disregard the conventional methods taught at the universities, and only refer to the theorems without proofs, we can solve some nice and interesting number theory problems with relatively few knowledge about the topic. On the one hand, this kind of academic outlook motivates the more talented students and those who are committed to learn mathematics, on the other hand, it helps them to overcome the difficulties which usually show up when the students go to university after secondary school.

\section{Orsolya Szabó: Statistical Analyses Used In Rural Tourism Research}

The research of rural tourism and of tourism generally often applies statistical methods. In spite of the high number of literature available that helps those who are engaged in the quantitative research of tourism, the third your student of our faculty are afraid of using statistical methods when preparing the primary or secondary research of their BSc thesis on rural tourism. The purpose of my study is to present the statistical methods that can be used in rural tourism research especially in the case of a BSc thesis.

FERENC SZILÁgyi: Using quantitative methods in the research on catchment areas. Sectional division of the Romanian-Hungarian border

Subsequent to the regime change and due to the start of the integration process, Central European state borders have been completely reinterpreted. While they formerly had a strongly marked dividing role, nowadays state borders are becoming virtual and those acting as barriers are continuously withering away. Nowadays, Hungary has already become a member of the Schengen area and against all political procrastination Romania's accession is also imminent. With 
the homogenizing economic area urban hierarchy has also changed since the subjects under discussion are the urban systems of the neighbouring countries which have been mostly isolated so far, being touched by the breath of integration as well. As it is to be expected, a hierarchical relationship will develop between the settlements located on the different sides of the border. Both states and larger towns will have to show due regard for the territories located in their immediate vicinity but on the other side of the border. These redefined attraction zones may constitute the engine of the integration. In my presentation I propose some quantitative methods which may be used in the research on border division.

JUDIT SzILÁGyi: The introduction of basic number theoretical concepts using IBL activities based on a Van Hiele type framework

In this presentation we detail a Van Hiele type model for the teaching of basic number theoretical concepts (divisors, prime numbers) and based on this model we also highlight some IBL activities that support the transitions between the first 3 levels of our model. From the perspective of the model these activities are in contrast with most of the traditional teaching materials because most of traditional teaching materials can be assigned to level 2 or 3 , so they do not support students at inferior levels. Our activities and teaching materials were tested in several events and activities with different target groups starting from 5 th grade students to mathematics teachers. In the last part of the presentation we also present some difficulties, challenges, conclusions from the viewpoint of a practicing teacher and some connections with the IBL concept developed in the framework of the PRIMAS project.

\section{VIKTOR TAKÁCS: Block programming languages}

Graphical programming environments, like LabView, Scratch, AppInventor for Android have become very popular between amateur computer programmers. In The Massachusetts Institute of Technology several master theses have been inspired by the topics of graphical programming environments, especially block languages, which projects are the most preferred at MIT. These programming environments are much more spectacular, friendly and have the potential for new perspectives education, other than other languages we traditionally taught. In August of 2012 Google Inc. made the first block language available, which runs in the "cloud". Its name is Blockly. Google's traditional marketing trick is that besides making applications with Blockly we can develop our own domain-specific programming language by making own blocks.
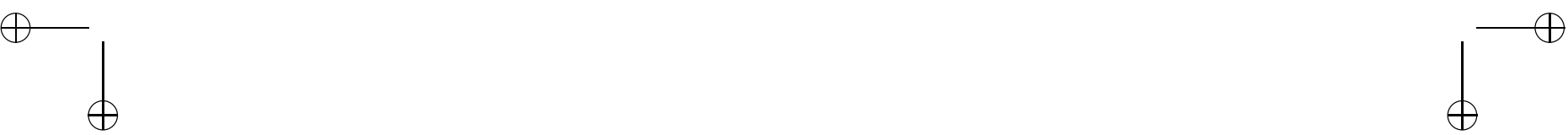
In this presentation we introduce Blockly, and the use of this language in primary school mathematics: we solve word problems and "What does the machine do?" problems (evolving function concepts) by Blockly.

CsabA TAMÁsI: Teaching centroids in theory and in practice

In this presentation I present a practical teaching experiment and I focus on some outcomes, experiences, consequences that might be useful both from the perspective of a practicing teacher and from the viewpoint of a developer, who is intended to design teaching materials suitable for IBL activities in upper secondary school. During the presented activity the participants had the opportunity to connect a real life problem with the corresponding abstract mathematical notions. The basic problem situation is to determine the centroid of simple systems such as: a system formed by two or more point wise objects, polygonal shapes and polygons. The surprise is arising by starting from practice and understanding gradually why the experimental centroid is different from the theoretical one. It is very interesting that most of the participants are trapped in their misconceptions about centroids. These misconceptions are facilitated also by the language we use and they appear rationally due to the idealistic suppositions we usually use in school. We also present some alternative ideas developed by students, for solving related problems.

\section{JUdit T. NAGY: Web-usage in higher education - a survey in Hungary}

We carried out a nationwide survey in Hungary between 2011 and 2012 to map computer-based support to teaching and learning in higher educational institutions of economics. In this article we give an account of the results of our research. We present the extent of web usage in organizing learning and courses as well as the role of the computer and the extent of computer usage in teaching-learning processes. We also examine the usage of e-communication and evaluation systems; describe the e-course content in use, possible e-learning solutions, e-learning environments (their specific functions) and other software systems. With the analysis of the results, our aim is to identify the typical computer usage patterns of the institutions and to examine what factors and to what extent computer usage linked to teaching depends on.

\section{ANIKÓ VÁGNER: Software aided education of $P L / S Q L$ programming language}

I introduce an educational method, which is applied in the course named Advanced DBMS 1 in Software Engineering BSc program at University of Debrecen. According to the traditional educational style the teacher works at the whiteboard and shows tasks and their solutions to the students. The students have no 
opportunity to tell their thoughts to the teacher. They will not get any feedback from the teacher about their work. Many books about didactic questions suggest to the teacher, that the students have to learn in an active way instead of a passive way. I have changed the traditional educational style of the practice for a method, where students practise the tasks alone given by the teacher, the teacher gives feedback about the solutions. The students have to use a database, because the actual course is about databases. This is the best tool for administration of tasks and their solutions. The students can get the tasks in the database, and give the solutions in the database as well. The teacher can accept or refuse the solutions in the database. A software product has been developed and applied to make this work easier. I have taught the subject in two groups in the previous semester. In the first group I have tried out the method, which uses the software product. In the second group I have taught according to the traditional style. I introduce the software and the organization of the lessons and the semester in case of both educational methods.

\section{FERENC VÁRADY: The exponential function and its applications}

I have been teaching mathematics for more than a decade in the Hungarian educational system, and I have found that many students find it difficult to understand the exponential function, the exponential process, and it is even more difficult for the students to interpret, to model and to solve these. So I was looking for a method that allows students from the very beginning to understand and to keep track of the structure and essentials of exponential processes. I have examined a number of textbooks available in Hungary and a German textbook of the region Baden-Württemberg as well. After studying several mathematical methods, finally I decided on Freudenthal's Realistic Mathematics Education. Naturally, much emphasis was placed to combine this method with the basic mathematics curriculum in Hungary, so I developed the 33 lessons available in class 11 for the topics power, root, and exponential and logarithmic functions according to this. In this developmental experiment particular attention was paid to possible leftbehind students during the learning process and the real understanding of the background while dealing with the tasks.

\section{Magda VÁRterész: Proof schemes and techniques - a clear logical background}

Proving mathematical theorems often causes a problem for students. A proof (derivation) is nothing more than a series of statements in which each one is either a premise (axiom or hypothesis) or a statement obtained by applying certain logical rules to earlier statements. Axioms of a theory can express complicated 
facts, but the proof is a relatively simple derivation of the items and indeed formal. The difficulty is that the deduction should be found by the student. In this presentation, an important derivation scheme developed in 1935 by Gerhard Gentzen is explained in everyday language. Simple examples to demonstrate the use of the derivation schemes in the proof of theorems will also be presented.

\section{Zoltán Zakota: What and how to teach about the Information Society?}

The term "information society" has followed a really spectacular trajectory in the last decades. From being a flaming journalistic term it has declaimed becoming one of the well-worn commonplaces. Despite this, its meaning, as used in social sciences and politics, has stabilized, thus becoming operational. The European Union has played an important role in filling the term up with concrete meaning, by making it one of the core strategic concepts of its sectorial politics. When talking about connections between information society and education, we have to distinguish between two fundamental realms. One of them refers to the impact of information society on education, to the ability of incorporating new digital technologies in the teaching practice. The second one refers to the ways in which notions and elements of information society can be integrated in the educational process. All these together form a highly complex issue due, partly to the diversity, partly to the time barriers implied. My presentation aims to present both positive and negative approaches to these two topics, with special emphasis on the second one.

\section{List of participants}

1) Marián Ambrozy, Private High School Spišská Teplica, Spišská Teplica, Slovakia, ambrozy.marian@gmail.com

2) András Ambrus, Eötvös L. University, Mathematics Teaching and Education Centre, Budapest, Hungary, ambrus@cs.elte.hu

3) Szilárd András, Babeş-Bolyai University, Faculty of Mathematics and Informatics, Cluj-Napoca, Romania, andraszk@yahoo.com

4) Eszter Árokszállási, Vak Bottyán High School, Paks, Hungary,

arokszallasieszter@gmail.com

5) Tünde Baranyai, Babeş-Bolyai University, Faculty of Psychology and Educational Sciences, Satu Mare, Romania, baratun@yahoo.com 
6) Krisztina Barczi, Neumann János High School, Eger, Hungary, bkrixta@gmail.com

7) Mihály Bessenyei, University of Debrecen, Institute of Mathematics, Debrecen, Hungary, besse@science.unideb.hu

8) Judit Boda, University of Debrecen, Institute of Earth Sciences, Debrecen, Hungary, boda.judit@science.unideb.hu

9) Ignác Bontovics, Szent István University, Faculty of Applied Arts and Pedagogy, Szarvas, Hungary, bignacz@gmail.com

10) Katalin Bubnó, University of Debrecen, Faculty of Informatics, Debrecen, Hungary, bubno.kati@gmail.com

11) László Budai, II. Rákóczi Ferenc High School, Szécsény, Hungary, budai0912@gmail.com

12) Kristina Cafikova, Constantine the Philosopher University in Nitra, Slovakia, kristina.cafikova@ukf .sk

13) Anikó Csákány, Budapest University of Technology and Economics, Institute of Mathematics, Budapest, Hungary, csakany@math.bme.hu

14) Hajnalka Csapó, Márton Áron High School, SimpleX Association, Miercurea Ciuc, Romania, chajnalka@yahoo.com

15) Edith Debrenti, Partium Christian University, Oradea, Romania, edit.debrenti@gmail.com

16) József Fogarasi, Partium Christian University, Oradea, Romania, fogarasi.jozsef@aki.gov.hu

17) Edit Földesi, BÉKSZI Trefort Ágoston Vocational High School, Békéscsaba, Hungary, f.ditti@vipmail.hu

18) Katalin Földesi, Malardalens Högskola, Sweden, katalin.foldesi@mdh.se

19) István Füvesi, University of Szeged, Department of Informatics, Szeged, Hungary, fuvesi@inf.u-szeged.hu

20) Ján Gunčaga, Catholic University in Ružomberok, Faculty of Pedagogy, Ružomberok, Slovakia, jan.guncaga@ku.sk

21) Eszter Herendiné Kónya, University of Debrecen, Institute of Mathematics, Debrecen, Hungary, eszter.konya@science.unideb.hu

22) Sara Hershkovitz, The Center for Educational Technology, "Shaanan" Academic Religious Teachers' College, Tel Aviv, Israel, Sarah@cet.ac.il 
23) Tünde Kántor, University of Debrecen, Institute of Mathematics, Debrecen, Hungary, tkantor@science.unideb.hu

24) Hajnalka Kánya, Partium Christian University, Oradea, Romania, kanyahajnalka@partium.ro

25) Anna Klingné Takács, Kaposvár University, Faculty of Economic Science, Kaposvár, Hungary, klingne.anna@ke.hu

26) Imre Kocsis, University of Debrecen, Faculty of Engineering, Debrecen, Hungary, kocsisi@eng. unideb.hu

27) Judit Kollár, Budapest Buisness School, College of Finance and Accountancy, Budapest, Hungary, zolna1@freemail.hu

28) Lilla Koreňová, Comenius University, Bratislava, Slovakia, korenova@fmph.uniba.sk

29) Béla Kovács, Partium Christian University, Oradea, Romania , profdrkovacs@yahoo.com

30) Veronika Kovács, Eötvös Lorand University, Faculty of Science, Budapest, Hungary, vkovacs@cs.elte.hu

31) Péter Körtesi, University of Miskolc, Miskolc, Hungary, matkp@uni-miskolc.hu

32) Károly Lajkó, University of Debrecen, Institute of Mathematics, Debrecen, Hungary, lajko@science.unideb.hu

33) Gyula Maksa, University of Debrecen, Institute of Mathematics, Debrecen, Hungary, maksa@science.unideb.hu

34) Ilona Máté, The Lower-Secondary School of Paptamasi, Paptamasi, Romania, mateilona@yahoo.com

35) Sándor Molnár, Budapest Buisness School, College of Finance and Accountancy, Budapest, Hungary, Molnar.Sandor@pszfb.bgf .hu

36) Katalin Munkácsy, Eötvös L. University, Mathematics Teaching and Education Centre, Budapest, Hungary, katalin.munkacsy@gmail.com

37) Edit Nagy, Partium Christian University, Oradea, Romania, nagyedit@partium.ro

38) Örs Nagy, Elektromure Technical High School, Tărgu Mures, SimpleX Association, Miercurea Ciuc, Romania, nagyors@gmail.com

39) Ilona Oláhné Téglási, Eszterházy Károly College, Faculty of Mathematics and Informatics, Eger, Hungary, olahneti@ektf .hu 
40) Dorka Palotay, Eötvös Lorand University, Faculty of Science, Budapest, Hungary, dpalotay@cs.elte.hu

41) Enikő Pozsonyi, Eötvös Lorand University, Faculty of Science, Budapest, Hungary, pozsiencsi@gmail.com

42) Edita Partová, Selye János University, Komárno, Slovakia, partova@gmail.com

43) Erika Perge, University of Debrecen, Faculty of Engineering, Debrecen, Hungary, perge@ang.unideb.hu

44) Richárd Rakamazi, Neumann János High School, Eger, Hungary, raka82@gmail.com

45) Gabriella Stark, Babeş-Bolyai University, Faculty of Psychology and Educational Sciences, Satu Mare, Romania, ngabriella77.gmail.com

46) Csaba Szabó, Eötvös Lorand University, Faculty of Science, Budapest, Hungary, csaba.cs.elte.hu

47) Orsolya Szabó, Partium Christian University, Oradea, Romania, orsolya_szabo@yahoo.es

48) Erzsébet Szász, Partium Christian University, Oradea, Romania, zsokisz@yahoo.com

49) Ferenc Szilágyi, Partium Christian University, Oradea, Romania, szilfester@gmail.com

50) Judit Szilágyi, Báthory István High School, Cluj Napoca, SimpleX Association, Miercurea Ciuc, Romania, szwoody@yahoo.com

51) Viktor Takács, University of Debrecen, Debrecen, Hungary, takacs.viktor@fin.unideb.hu

52) Csaba Tamási, Márton Áron High School, SimpleX Association, Miercurea Ciuc, Romania, tamasics@yahoo.com

53) Margit Tarcsi, Debrecen Reformed Theological University, Kölcsey Institute of Primary Education, Debrecen, Hungary, tarcsim@kfrtkf.hu

54) Štefan Tkačik, Catholic University of Ruzemberok, Ruzemberok, Slovakia, tkacik@ku.sk

55) Judit T. Nagy, Edutus College, Budapest, Hungary, tnagy. judit@gmail.com

56) Anikó Vágner, University of Debrecen, Faculty of Informatics, Debrecen, Hungary, vagner .aniko@inf .unideb.hu 


$$
\text { "tmcs-konya-report" — 2013/5/24 — 17:07 — page } 143 \text { — \#21 }
$$

57) Ferenc Várady, Budapest Buisness School, College of Commerce, Catering and Tourism, Budapest, Hungary, varadyf@gmail.com

58) Magda Várterész, University of Debrecen, Faculty of Informatics, Debrecen, Hungary, varteresz.magda@inf .unideb.hu

59) Kitti Vidermanova, Constantine the Philosopher University in Nitra, Slovakia, kvidermanova@ukf.sk

60) Zoltán Zakota, Partium Christian University, Oradea, Romania, zzakota@partium.ro

61) Gabriella Zsombori, Sapientia Hungarian University of Transylvania, Faculty of Economic and Human Sciences, Miercurea-Ciuc, Romania, zsomborigabriella@gmail.com

(Compiled by E. Herendiné Kónya and E. Debrenti) 